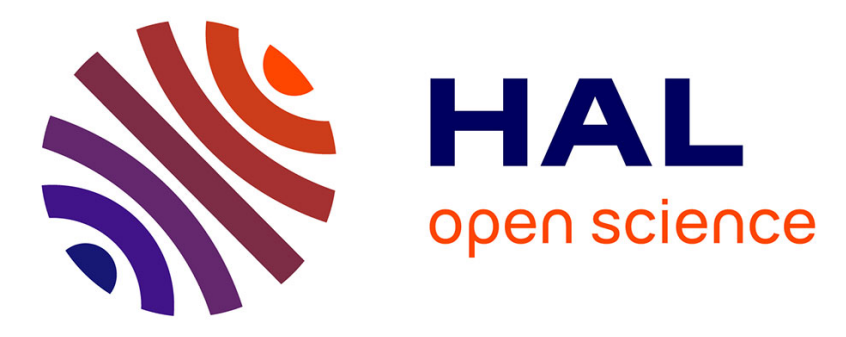

\title{
The Platformization of Labor and Society
}

Antonio A. Casilli, Julian Posada

\section{To cite this version:}

Antonio A. Casilli, Julian Posada. The Platformization of Labor and Society. Mark Graham \& William H. Dutton. Society and the Internet. How Networks of Information and Communication are Changing Our Lives (second edition), Oxford University Press, pp.293-306, 2019, 9780198843504. halshs-01895137

\section{HAL Id: halshs-01895137 https://shs.hal.science/halshs-01895137}

Submitted on 14 Oct 2018

HAL is a multi-disciplinary open access archive for the deposit and dissemination of scientific research documents, whether they are published or not. The documents may come from teaching and research institutions in France or abroad, or from public or private research centers.
L'archive ouverte pluridisciplinaire HAL, est destinée au dépôt et à la diffusion de documents scientifiques de niveau recherche, publiés ou non, émanant des établissements d'enseignement et de recherche français ou étrangers, des laboratoires publics ou privés. 
Antonio A. Casilli \& Julián Posada Gutiérrez (2019). The Platformization Of Labor and Society, in M. Graham \& W. H. Dutton (eds.), Society and the Internet; How Networks of Information and Communication are Changing Our Lives, (2nd edition), Oxford, UK: Oxford University Press, [forthcoming].

\title{
The Platformization of Labor and Society
}

\author{
Antonio A. Casilli and Julian Posada
}

\begin{abstract}
This chapter focuses on the role of digital intermediaries in shaping technology, society, and economy under what Casilli and Posada call 'the paradigm of the platform'. They trace the historical relationship between platforms, markets, and enterprises to demonstrate the role of algorithms in matching users, pieces of software, goods, and services, and how platforms can create value from the content and data generated by users. Their primary argument is that platforms play a fundamental role in establishing a digital labor relationship with their users by allocating underpaid or unpaid tasks to them. In order to enable and coordinate users' contributions, platforms need to standardize and fragment ('taskify') labor processes. The authors conclude by bighlighting the link between platformization and automation, with the tech giants employing their users' data to produce artificial intelligence and machine-learning solutions to an expanding range of problems.
\end{abstract}

Keywords: platformization, data, algorithms, automation, digital labor, precariat. 


\section{$<\mathrm{H} 1>$ Introduction}

The notion of the 'platform' established itself in the tech industry in the early 2000s to designate digital intermediaries that match persons, information, and goods (Evans et al. 2006). The term, which was initially synonymous with computer 'architecture', was mainly borrowed from the latter discipline (Hennessy \& Patterson 1990, Baldwin \& Woodard 2009). Thus, a platform can be mainly characterized as a software or hardware infrastructure on which users, companies, and even governments build applications, services, and communities.

In his book Platform Capitalism, Nick Srnicek (2017) distinguishes several types of platforms. Some run popular consumer services: advertising platforms like Google extract and analyze information from users and sell ad space; product platforms, like Spotify, transform goods into services accessible to subscribers; and lean platforms, like Airbnb, do not own the material assets from which they make profit. Other platforms cater exclusively to businesses: industrial platforms, like GE or Siemens, transform traditional manufacturing into internet-based processes, while cloud platforms, like Amazon Web Services (AWS), rent data storage and computing power.

In light of the success of these services, platforms have established themselves as an organizational and technological paradigm both for tech industry pure play companies and for companies, state- and privately-owned, that are not inherently technological, but whose business models transition towards platform-bases strategies. For instance, insurance companies (such as Admiral), retail (such as Tesco) and transportation (such as French state-owned SNCF), are increasingly relying on platforms to coordinate and acquire further data on their clients.

In this chapter we will focus on five aspects of the platformization phenomenon. First, the emergence of platforms as a replacement for pre-existing modes of economic coordination. Second, the way platforms rely on data to create value. Third, how data are extracted from multitudes of users in the form of 'digital labor'. Fourth, how users' behavior is fragmented and reduced to standard tasks. And fifth, 
how trends towards 'datafication' and 'taskification' are the sinews of contemporary developments in automation and artificial intelligence. These five pieces provide a basis for addressing their societal implications.

\section{$<\mathrm{H} 1>1$. Platforms emerge as a response to deficiencies of markets and enterprises}

Although platforms are grounded in digital technology, they primarily emerge as a response to long-term social and economic developments, particularly the diminishing relevance and efficiency of enterprises and markets, two traditional methods for organizing human productive activities.

Markets act as coordinating mechanisms, designed to enable several groups of buyers and sellers to interact. Conventionally, they achieve their goal using prices, thus matching individuals and organizations willing to provide a particular good or service in exchange for a certain amount of money (supply), with others who are willing to spend said amount (demand). Recent devastating crises that have hit both financial and goods markets have undermined collective confidence in their reliability as coordination mechanisms. Moreover, they have shown the limitations of prices to adequately represent the value of the goods and services negotiated on the markets. Some commentators describe this situation as a 'crisis in the representation of value' (Muniesa 2011: 33).

Anthropologist Jane I. Guyer (2016) argues that, by losing its relevance as a mechanism for coordinating human actions, the market has increasingly become 'abstract' and disconnected from individual experiences. Previously depicted as a physical space where localized relationships occurred ('the marketplace'), the market has been increasingly reduced to an impersonal force governed by opaque rules that transcend individual comprehension ('the economy') (Graeber 2009). By contrast, platform components and applications present themselves as technological solutions with an actual impact on users' lives. Especially when they take the shape of mobile 
applications, they are perceived as capable of offering concrete solutions to real-life problems: for instance, by connecting individuals to friends and loved ones via Facebook or Tinder, by helping them beat traffic on Waze, or by providing them with tips on the best deals like in ShopSavvy or Trivago.

As markets detach themselves from individual experience, another perceived failure looms: that of traditional enterprises to create wealth and innovation. Between 1980 and 2000, in the wake of financial capitalism, established firms faced harsh global competition and had progressively given up their usual 'retain \& invest' models, based on the internalization of assets to develop innovative value-added services and products. Instead, they have opted for narrower 'downsize \& distribute' business strategies, where principles of lean management coexist with the massive outsourcing of labor and production processes to generate short-term profitability for their shareholders (Segrestin \& Hatchuel 2012). During the 2000s, for instance, US top businesses have sacrificed $R \& D$ programs by expending up to 94 percent of their revenue in stock-market manipulation, mainly buying back their shares to artificially increase their sales-per-share (Lazonik 2010).

These tendencies have eroded the role of traditional enterprises as drivers of economic growth and have accelerated their replacement by the new platform-based social and technological paradigm. Instead of focusing on core competencies, business identity, and flagship products, digital platforms adopt a more dynamic (even opportunistic) approach. They act as meta-organizations that try and discard products in a pragmatic and sometimes volatile way (Ciborra 1996). For example, Yahoo! has pivoted over time from a search engine to a news portal. Before becoming a top microblogging platform, Twitter was a podcast delivery service. Also, Google has launched and then dispensed with several services, from the messaging software Google Wave to the wearable device Google Glass.

Another characteristic of enterprises is their reliance on hierarchies to curb transaction costs (Williamson 1967). This strategy implies a sharp distinction between the inside and the outside of a firm: the former is regulated by hierarchies 
and subordination, while the latter is directed by the freedom to cooperate. Instead of complying with traditional companies' 'hierarchical control', new platformed organizations blur the boundaries between the interior and exterior of firms and are predicated on promises of horizontal coordination and independent access to material and informational resources. When they sign up on Etsy or eBay, for example, all users are assumed to participate on equal footing in the functioning of the platforms, none of them acting as a supervisor or a line manager. Furthermore, the terms they sign do not include exclusivity clauses that restrict their usages inside a single platform.

Despite that, a digital platform is less of a sharp departure from previous paradigms and more like a hybrid organization, halfway between a market and an enterprise. For instance, Amazon presents itself as a traditional enterprise, with a highly hierarchical structure that often manifests itself in a 'bruising' work culture (Kantor \& Streitfeldaug 2015), and the reinvestment of financial gains into shareholders' dividends. However, at the same time, it runs a thriving marketplace, where it connects sellers and buyers.

Like enterprises, platforms rely on intricate, multi-layered, and ultimately hierarchical features (Gillespie 2010). Like markets, they select goods, manage information, or even establish prices of its services. Uber's surge pricing algorithm is emblematic of this: the overall number of users launching its app on their smartphone allows Uber to estimate the number of people who are 'on the market' at a given time in a specific area. The platform operates on a just-in-time basis and, unlike taxi companies, it does not manage a stable fleet of vehicles or has access to reserved parking spaces. In order to turn that potential demand into actual rides, enough cars must converge in the same neighborhood. To coordinate supply and demand, the price of a trip is not calculated from distance and other criteria, such as the time or the type of vehicle, but it is multiplied by a coefficient that can range from 1 to 50. Thus, Uber does not wait for passengers and drivers to come up with a price autonomously or to set a fixed price for its rides but instead uses dynamic 
pricing (Hall, Kendrick \& Nosko 2015). This example highlights another essential feature of digital platforms: they coordinate their components through algorithmic matching rather than through simple price adjustment. Prices are not the results of free transactions between sides of a given market since a real-time algorithmic arrangement sets them on the platform.

In the next section of this chapter, we will argue that algorithmic matching rests on the use of data to create value-added services. Data are, in turn, created by the ambiguous consented and conscious participation of their users.

\section{$<\mathrm{H} 1>2$. Platforms capture users' content and data to generate value}

The network structure of platforms enables them to appropriate the fruit of the activity of the multiple parties on each transaction, instead of extracting it from relations of productive subordination, as in the case of firms (Ryall, 2013). On the one side, platforms monetize their users' interactions. Several, like Facebook or Google, make users' information available to paying partners. Some, like Netflix, make their customers purchase a subscription to their services. Others take a percentage of the revenue that the users generate, like in the case of Amazon whose fees can reach 20 percent of the price of a product sold in its catalogue.

Most importantly, platforms capture value by collecting the output of their users' participation. As tech investor and author Tim O'Reilly puts it: 'the secret to the success of bellwethers like Google, Amazon, eBay, Craigslist, Wikipedia, Facebook, and Twitter is that each of these sites, in its own way, has learned to harness the power of its users to add value to (...) its offerings' (O'Reilly 2011: 13). One of the first mainstream search engines, Yahoo!, classified and referenced millions of websites according to categories established by multitudes of early service adopters. YouTube users produce, upload, rate videos, and even review them for inappropriate content so that the recommendation algorithm can make automated suggestions. 
Value capture is a strategy the platforms have adopted since the dawn of the World Wide Web (Teece \& Linden, 2017). User-Generated Content (or UGC) is one of the most visible forms of appropriation of user participation for commercial use. The major platforms of the 2000s (Friendster, Myspace, YouTube, and Facebook in Western countries and Orkut, QQ, Sina Weibo, and VKontakte in emerging ones) owe their success to billions of 'volunteer' users that over the years have produced their text, images, sounds, and videos.

However, user-generated content is not the only source of value for digital platforms. Value capture means that any information provided by the users has a commercial advantage. Such information can also be attached to the products and services that circulate on a platform: ratings, engagement statistics, and commentaries help discriminate among sellers on e-commerce websites or service providers on ride-hailing apps.

Moreover, the harvesting of data and metadata have been a primary source of userrelated value for tech companies. Data can be described as any information about the users requested by the platforms or volunteered by the individuals: a name, a telephone number, a password, but also the likes on specific content and the messages in someone's inbox. Metadata are information about other data: for instance, a tag on an Instagram picture, the IP address attached to a Wikipedia edit, or the description under a YouTube video.

This information is continuously monetized: sold or made accessible for a fee to brands and advertising networks, to other businesses, and even to governments for the surveillance of their population. Despite their marketing and communications strategies, platforms insist on the technical aspects of their success (their algorithms, their servers, or their drones), and their ability to extract contents, data, and metadata from their users is paramount. Their growth does not depend on a single product or service, but on the overall value that they can extract from the personal data they possess, the dynamism of their communities, and the relevance of the services they 
offer. In the following section we analyze how, by stimulating user participation, platforms end up creating a new form of inconspicuous digital labor.

\section{$<$ H1 $>$ 3. Platforms' prosperity is predicated on their capacity to put their users to work}

The capture of material and immaterial resources generated by communities of users can be considered either as a form of participation and 'co-creation' or as a way of putting users to work to turn their participation into 'digital labor' (Scholz 2012). In a landmark publication, Tiziana Terranova describes digital labor as the 'free labor on the net' and lists activities falling under this description as 'building Web sites, modifying software packages, reading and participating in mailing lists, and building virtual spaces' (2000: 33). Beyond this initial characterization, as we have discussed, digital labor cannot be limited to a pro-bono production of content, since activities performed by users, from filling in their profiles to drawing up a friend list, represent lucrative opportunities for tech giants.

In a practical sense, what digital labor encompasses is not confined to free internet labor, but embodies a range of non-standard forms of production, from semiprofessional amateurism to monetized leisure, and from unpaid click-work to 'gigs' and freelancing. This type of labor relations mediated by digital platforms locates productive activities outside of regular employment and spawns a variety of invisible or informal working arrangements which do not guarantee fundamental rights such as paid leave, retirement, safety, and most importantly, the right to be paid for one's contribution.

On social media, the production of information conventionally manifests itself in unpaid activities performed by users, so that online services can profit from every social media post, every gaming session, every comment, every photo uploaded. Insofar as 'both social media and the factory are products of capitalism and are, ultimately, adapted to its purposes' (Rey 2012: 401). This, of course, creates tensions 
with formal labor markets and exerts a pressure on professionals and specialized service providers.

One of the early experiments in digital labor on Facebook was Diaries, a 2007 TV series made up of montages of user-generated videos. Around it, Facebook developed a fruitful broadcast partnership with Comcast (Johnston 2007). The series served as advertising as well as a revenue source from the broadcasting rights. In the context of the reduction of the workforce in the media industry, according to Nicole Cohen (2008), the recourse to amateur content amounts to the outsourcing of content production to online multitudes of producer-consumers. This informal labor is so entangled with actual labor, that it is in redefining labor markets and eroding workfare protections, thereby prompting the emergence of new occupational identities built upon precarity and risk-taking.

Thus, the exclusive focus on free labor gives way to new evidence showing that digital labor is a continuum of unpaid, micro-paid, and poorly paid human activities, thus encompassing the kind of actions performed by users of participatory media as well as platform-based piecework (Casilli 2017).

The example of on-demand platforms such as Uber, TaskRabbit, Deliveroo or Airbnb is emblematic: based on mobile apps allocating material and informational resources in real-time, they connect customers with independent goods or service providers. These platforms act as algorithmic match-makers between one group of users (riders, home-owners, customers, or guests) and those who secure transportation, maintenance, catering, or accommodation. On-demand apps are incredibly dependent on material human labor, whether direct (a category of users performing physical tasks such as driving, delivering, or cleaning) or indirect (a category of users affording an asset like an apartment, a car, or a piece of equipment). Yet, this material labor is deeply interconnected to the information economy platforms thrive upon. Users are not only pressured to provide services, but also to create content, data, and metadata. For instance, Airbnb encourages its members to participate beyond the hospitality service. It acts as social media, where both hosts 
and guests have to upload volumes of photos, texts, messages, and evaluations. Users also have to provide geolocation data or socio-demographic information (such as their name, address, or age). To satisfy its data needs, Airbnb has partnered with other platforms, for instance with Foursquare to employ its geolocated images in its city guides (Garun, 2016).

\section{$<$ H1 $>4$. To generate data, platforms 'taskify' labor processes}

In order to generate data and to allow algorithmic matching of different groups of individuals, platforms encourage the 'taskification' of work, or the reduction of human activities to the smallest conceivable unit of execution (virtually, a click), to facilitate interconnection and value capture. Platforms operate in ecosystems where consumers (e.g. those buying flights and booking hotels on Expedia), interact with companies (like hotels or airlines), smaller platforms (such as those which run ads and sponsored links on websites and mobile), or public infrastructures (e.g. airline schedules databases). All these individuals and organizations are components of the platform, and they all have to perform interoperable actions. The reduction of human activity to normalized and simplified elements is necessary for platforms to coordinate and access an ecosystem composed of individuals, communities, apps and databases.

The standardization and the fragmentation of previously complex and specialized processes are essential to run a platform ecosystem where the activities of users fit in and are synchronized with others (Gray 2016). Twitter, for example, is a medium that employs short of 3,860 people worldwide as of 2018 , has no actual editorial staff, and entrusts its users with the responsibility of producing and circulating content. The extreme standardization of its service, the publication of messages of less than 280 characters, has allowed its growth from 0 to 335 million accounts over the span of 12 years since its inception in 2006. By outsourcing mostly fragmented and 
effortless tasks of content selection and enrichment to its users (likes, retweets, and hashtags), the platform can efficiently run existing accounts, and easily add new ones.

Despite apparent similarities, the platform-based 'taskification' represents a departure from the 20th century Taylorism where the ideal of industrial-era scientific management sought to normalize work in units of time in order to reduce the internal complexity of the factory. Heterogenous individual contributions (like different crafting styles or quality standards) were better integrated into the collective effort to produce value internally. In contrast, platform-based tasks are mainly connected to outsourcing, which becomes an all-pervasive way of functioning. As far as platforms tend not to produce internally the good and services they provide, they reduce to bits and sublets added-value tasks to their ecosystems. Nevertheless, it is a new type of outsourcing that takes place on platforms: it is not an individual or an organization that becomes a subcontractor, but an entire network, multitudes of production units, all qualified as users.

Furthermore, the taylorist strengthening of bureaucracies and the simplification of labor processes were designed to develop critical skills within a company's workforce. Platforms, by contrast, bring forth a new division of labor which ensures a high level of productivity by involving users, consumers, and freelance workers into the production. Those who perform tasks are not specialized professionals with an obligation to achieve results, but casual, disposable, and virtually low-skilled performers that may not even require a small amount of pay. Standardization and segmentation of labor processes are thus instrumental in facing the uncertainty that this new division of labor entails.

\section{$<\mathrm{H} 1>5$. Platform-based labor is the secret ingredient of automation}

A final consequence of platformization is their use of taskified labor to shape up business automation processes. Since platforms reduce labor to tasks—or rather to micro-tasks_-a vast amount of data and metadata increasingly fuels human-based 
computation. This technique allows machines to crowdsource simple operations like tagging, flagging, or adding content descriptions to human users.

Maybe the best-known platform specialized in micro-tasks is Mechanical Turk, a service created by Amazon in the mid-2000s to provide services like data refinement and enrichment, image recognition, and speech-to-text. Its users are classified as 'consumers-workers' and are usually paid as little as one or two cents to perform tasks that vary in complexity (Hara et al. 2018).

Half-jokingly, the service was launched by Jeff Bezos (2006) as a way to produce 'artificial artificial intelligence'. In other words, automation performed by crowds of human users. Indeed, artificial intelligence should ideally execute the HITs (Human Intelligence Tasks) performed by Mechanical Turk workers. Nevertheless, too often expert systems and machine learning models lag beyond the commercial claims of their producers and their investors (Irani 2015). Despite the promises of 'full automation', human digital labor compensates the technical limitations of new intelligent solutions supposed to automate business processes. More broadly, the execution of micro-tasks is necessary to 'train' artificial intelligence (i.e. to calibrate machine learning models by providing them with millions of examples of human judgements, choices, and behaviors). To make automation possible, digital platforms recruit hundreds of millions of human beings as users, customers, participants, and — in some cases — cheap micro-workers.

The relationship between platforms, taskified digital labor, and automation can be better appreciated if we consider that, despite exaggerated claims by platform owners about a foreseeable 'strong AI' capable of simulating all human cognitive processes (Kurzweil 2010), present-day artificial intelligence is generally 'narrow AI' based on 'shallow' statistical learning methods (Hayes 2012). Apart from their application in manufacturing technologies (the 'smart factory') where they advance pre-existing automated physical processes of production, the most visible manifestations of these 'narrow' AI are represented by late-2010s 'virtual assistants'. Voice-activated systems such as Siri, Alexa, or Cortana can be found both in smartphones and in smart 
speakers. These mainstream devices popularize the use of applications, websites, and services that require machine learning methods to execute complex actions: to suggest and play music, to make a dinner reservation, or to switch off the lights to save energy. They purportedly operate without human intervention. Nevertheless, the autonomy of these systems needs to be measured against the need for human labor to correct and sort through users' requests. Armies of silent listeners and transcribers are hired every day to double-check the responses provided by virtual assistants or to compare human transcripts and computer recordings of the sentences uttered by users.

Facebook even tried to turn the concealed humans executing tasks that should be performed by machines into a selling point. In 2015, the Palo Alto giant launched 'M', a text-based virtual assistant which was described as a 'supercharged AI powered by humans' (Metz 2015). Although these humans were supposed to supervise the actual machine learning for a limited amount of time, three years later they still performed up to 70 percent of the tasks (Griffith \& Simonite 2018), a testament to the fact that full automation and human-level Artificial Intelligence are far from being the 'manifest destiny' of contemporary digital technologies (Feigenbaum 2003).

Evaluators, 'data wranglers', and human assistants of the virtual ones are recruited by and for platforms (Lenke 2016) and put to work in increasingly precarious working conditions. In some cases, they perform piecework on portals like Mechanical Turk, UHRS, RaterHub-which provide the tech giants Amazon, Microsoft and Google with micro-tasks and data, respectively. In other cases, they are paid on an hourly basis by global subcontracting platforms like Appen, Lionbridge, and Pactera.

However, a vast majority of tasks is performed pro bono by unpaid platform users. This is attested by the success of systems such as ReCAPTCHA which, under the pretext of detecting bots, has been duping users into 'training' an optical character reader software deployed to transcribe Google Books (Von Ahn et al. 2008) and more recently to train autonomous cars and sometimes military AI. Harvesting users' 
clicks and concealed micro-tasks to sustain machine learning products is a common strategy that Alphabet has been profitably using to enhance everything, from Google Search to Google Translator.

Present-day incarnations of artificial intelligence are thus heavily dependent on 'non-artificial' work to operate. Despite the common argument that 'machines are stealing our jobs', AIs are not replacing human beings, considering that they need them to exist and to overcome their limitations. In domains as diverse as healthcare, management, or leisure, machines cannot effectively learn unless they interact with platform users who correct their mistakes, reduce their bias, interpret their information, and perform actions in their place.

Insofar as present-day AI systems are conditioned by computing power, big data, and financial resources provided by digital platforms, they depend on the digital labor performed by their users, who complete the tasks that make machines 'intelligent'. They create new technological assemblages which externalize labor processes, thus turning previously paid services into 'unpaid consumption work' (Huws 2003). From this point of view, AI does not represent a continuation of early industrial laborsaving technologies like the spinning mules or the locomotives, but a close relative to more recent technologies, like the self-checkout machines and ATMs (Palm 2005). As in the cases of customer-activated and often semi-attended terminals, automation does not replace work but displaces it to an increasing number of unpaid workers or 'non-workers'. For example, operators misrepresented and misclassified as workers of a lesser kind (micro-workers, temps, contingent, precarious, non-specialized data workers, and content providers). Platforms are the technological and organizational mechanisms that allow this task allocation to take place-and this brand of shallow automation to pursue its course.

$<$ H1 $>$ Conclusion: Another platformization is possible 
In this chapter, we presented five aspects of the adoption of the platform paradigm in society and its consequences regarding business and market organization, labor and automation. The societal implications of platformization will continue to unfold over the near-future. While the outcomes are uncertain, it seems clear that there is a need to address the grievances and distortions digital platforms generate.

Despite being described as "technologically neutral", platforms are political in nature. One of the senses of the word 'platform' is precisely that of a set of principles constituting a blueprint for future policies (e. g. the 'platform' of a party or of candidate). Digital platforms should be reconciled with this original meaning so to assume the social responsibilities for their impact on society.

This implies that platforms cease to disguise the political decisions their owners and investors make every day (about what kind of information circulates, who gets the biggest share of the value they capture, whose rights and welfare are guaranteed) as the impartial workings of ever-accurate algorithms. In a sense, there is no algorithm-it's only somebody's decision. Thus, it comes as no surprise that one of the fiercest battles taking place today around platforms is to oblige them to be transparent, auditable, even 'loyal' to their users. These principles are now debated, advocated, and (in some European countries) enshrined in law (Sandvig et al. 2014; Gillespie 2018; French Official Journal 2016).

Recognizing the political nature of platforms also means conceding that their privately-owned, capital-driven model is far from being the only existing one. Public platforms exist and prosper, ranging from state-owned ones (see for example the controversial Indian biometric and demographic data platform Aadhaar) to those operating at both local and regional levels (see the cities partnering in the European Commission's Urban Data Platform). More promisingly, community-based or cooperative platforms are emerging all over the world. Some are embedded in the larger movement for the "digital commons" and try to recreate a sense of belonging and participation, beyond the commercial logics that regulate capitalist platforms. Others converge towards a distinctive brand of "platform cooperativism" (Scholz 
2016), based on collective ownership and governance of digital infrastructures. Principles of mutualism and solidarity can thus be coupled with platformization, especially to establish fairer working conditions and to limit the competition among “digital laborers" on platform-mediated tasks (Graham \& Woodcock 2018). 


\section{REFERENCES}

Baldwin, Carliss Y. \& C. Jason Woodard (2009). “The Architecture of Platforms: A Unified View". In Annabelle Gawer (ed.), Platforms, Markets and Innovation. Cheltenham, UK: Edward Elgar Publishing, pp. 19-44.

Bezos, Jeff (2006). "Opening Keynote and Keynote Interview”. MIT World special events and lectures, Sept. 27, <http://techtv.mit.edu/videos/16180opening-keynote-and-keynote-interview-with-jeff-bezos>.

Casilli, Antonio A. (2017). "Digital Labor Studies Go Global. Towards a 'digital decolonial turn"'. International Journal of Communication, 11(1): 3934-3954.

Ciborra, Claudia U. (1996). "The Platform Organization: Recombining Strategies, Structures, and Surprises". Organization Science, 7(2): 103-118.

Cohen, Nicole (2008). "The valorization of surveillance: Towards a political economy of Facebook". Democratic Communiqué, 22(1): 5-22.

Evans, David S., Hagiu, Andrei \& Richard Schmalensee (2006). Invisible Engines. How Software Platforms Drive Innovation and Transform Industries. Cambridge, MA: MIT Press.

Feigenbaum, Edward A. (2003). "Some Challenges and Grand Challenges for Computational Intelligence". Journal of the ACM, 50(1): 32-40.

French Official Journal (2016). Law No. 2016-1321 of October 7, 2016, "For a Digital Republic".

Garun, Natt (2016). "Airbnb will now use Foursquare photos in its city guides", The Verge, Dec. 7, <https://www.theverge.com/2016/12/7/13869010/airbnbbuys-foursquare-photos-city-guides $>$.

Gillespie, Tarleton L. (2010). "The Politics of 'Platforms". New Media \& Society, 12(3): 347-364.

Gillespie, Tarleton (2018). Custodians of the Internet Platforms, Content Moderation, and the Hidden Decisions That Shape Social Media. New Haven, CT: Yale University Press. 
Graeber, David (2009). "Debt, violence, and impersonal markets: Polanyian meditations". In Chris Hann, Keith Hart (eds), Market and Society. The Great Transformation Today. Cambridge, UK: Cambridge University Press, pp. 106-132.

Graham, Mark \& Jamie Woodcock (2018). "Towards a Fairer Platform Economy: Introducing the Fairwork Foundation”. Alternate Routes, 29(1): 242-253.

Gray, Mary L. (2016). "Your job is about to get 'taskified"”. Los Angeles Times, Jan. $8<$ http://www.latimes.com/opinion/op-ed/la-oe-0110-digital-turk-work20160110-story.html>.

Griffith, Erin \& Tom Simonite (2018). “Facebook's Virtual Assistant M Is Dead. So Are Chatbots". Wired, Jan. 8 <https://www.wired.com/story/facebooks-virtualassistant-m-is-dead-so-are-chatbots $/>$.

Guyer, Jane I. (2016). Legacies, Logics, Logistics: essays in the anthropology of the platform economy. Chicago IL: University of Chicago Press.

Hall, Jonathan, Kendrick, Cory \& Chris Nosko (2015). "The Effects of Uber's Surge Pricing: A Case Study". Paper presented at the workshop Designing the Digital Economy, Cambridge, MA, Microsoft Research New England, Oct. 24-25 <http://1g1uem2nc4jy1gzhn943ro0gz50.wpengine.netdna-cdn.com/wpcontent/uploads/2016/01/effects_of_ubers_surge_pricing.pdf > .

Hara, Kotaro, Adams, Abi, Milland, Kristy, Savage, Saiph, Callison-Burch, Chris \& Jeffrey Bigham (2018). “A Data-Driven Analysis of Workers’ Earnings on Amazon Mechanical Turk", Proceedings of the 2018 CHI Conference on Human Factors in Computing Systems, p.1-14, April 21-26, Montreal QC, Canada.

Hayes, Brian (2012). "The Manifest Destiny of Artificial Intelligence". American Scientist, 100(4): 282-287.

Hennessy, John L. \& David A. Patterson (1990). Computer Architecture. A Quantitative Approach. New York, NY: Elsevier. 
Huws, Ursula (2003). The Making of a Cybertariat: Virtual Work in a Real World. New York: Monthly Review Press.

Irani, Lilly (2015). “The cultural work of microwork”. New Media \& Society, 14(1): $137-152$.

Johnston, Garth (2007). "Comcast site teams with Facebook". Broadcasting \& Cable, 137(7): 16.

Kantor, Jodi \& David Streitfeldaug (2015). Inside Amazon: Wrestling Big Ideas in a Bruising Workplace. New York Times, Aug. $15 . \quad<$ http:// www.nytimes.com/2015/08/16/technology/inside-amazon-wrestling-big -ideas-ina-bruising-workplace.html>

Kurzweil, Ray (2010). The Singularity is Near: When Humans Transcend Biology. New York: Penguin.

Lazonick, William (2010). "Marketization, Globalization, Financialization: The Fragility of the US Economy in an Era of Global Change". 2010 BHC Meeting, Athens, Georgia, $27 \quad$ mars 2010 $<$ http:/ / citeseerx.ist.psu.edu/viewdoc/download?doi=10.1.1.628.1345\&rep=rep1 $\&$ type $=p d f>$.

Lenke, Nils (2016). "Part 1 - AI for customer care: Human assisted virtual agents get smart with big knowledge". Nuance - In the Labs, May 11 $<$ http://whatsnext.nuance.com/in-the-labs/human-assisted-virtual-agentsmachine-learning-improve-customer-experience/>.

Muniesa, Fabian (2011). "A flank movement in the understanding of valuation". Sociological Review, 59(2), pp. 24-38.

O'Reilly, Tim (2011). "Government as a Platform". Innovations: Technology, Governance, Globalization, 6(1): 13-40. 
Palm, Michael (2015). "The costs of paying, or three histories of swiping”. Pp. 5165, in Olivier Frayssé \& Mathieu O’Neil (eds.), Digital Labour and Prosumer Capitalism. The US Matrix, Basingstoke, UK: Palgrave Macmillan.

Rey, P. J. (2012). “Alienation, Exploitation, and Social Media”. American Behavioral Scientist, 56(4): 399-420.

Ryall, Michael (2013). "The New Dynamics of Competition". Harvard Business Review, 91(6): 80-87.

Sandvig, Christian, Hamilton, Kevin, Karahalios, Karrie \& Cedric Langbort (2014). "Auditing Algorithms: Research Methods for Detecting Discrimination on Internet Platforms". Paper presented to "Data and Discrimination: Converting Critical Concerns into Productive Inquiry," preconference at the 64th Annual Meeting of the International Communication Association. May 22; Seattle, WA, USA

Scholz, Trebor (2012) (ed.). Digital Labor: The Internet as Playground and Factory. New York, NY: Routledge.

Scholz, Trebor (2016). Platform Cooperativism. Challenging the Corporate Sharing Economy, New York, NY: Rosa Luxemburg Stiftung.

Segrestin, Blanche \& Armand Hatchuel (2012). Refonder l'entreprise, Paris : Éditions du Seuil.

Srnicek, Nick (2017) Platform Capitalism. Cambridge, UK: Polity Press.

Teece, David J. \& Greg Linden (2017). "Business models, value capture, and the digital enterprise". Journal of Organization Design, 6(8) $<$ https://jorgdesign.springeropen.com/articles/10.1186/s41469-017-0018-x>.

Terranova, Tiziana (2000). "Free Labor: Producing Culture for the Digital Economy". Social Text, 18(2): 33-58.

Von Ahn, Luis, Maurer, Benjamin, McMillen, Colin, Abraham, David \& Manuel Blum (2008). "reCAPTCHA: Human-Based Character Recognition via Web Security Measures". Science, 321(5895): 1465-1468. 
Williamson, Oliver E. (1967). "Hierarchical Control and Optimum Firm Size". Journal of Political Economy, 75(2): 123-138. 